BMJ Open

Respiratory

Research

\section{Exploratory cost-effectiveness model of electromagnetic navigation bronchoscopy (ENB) compared with CT- guided biopsy (TTNA) for diagnosis of malignant indeterminate peripheral pulmonary nodules}

To cite: Rickets W, Lau KKW, Pollit V, et al. Exploratory cost-effectiveness model of electromagnetic navigation bronchoscopy (ENB) compared with CT-guided biopsy (TTNA) for diagnosis of malignant indeterminate peripheral pulmonary nodules. BMJ Open Resp Res 2020;7:e000595. doi:10.1136/ bmjresp-2020-000595

Received 26 March 2020 Revised 4 June 2020 Accepted 26 June 2020

Check for updates

(C) Author(s) (or their employer(s)) 2020. Re-use permitted under CC BY-NC. No commercial re-use. See rights and permissions. Published by BMJ.

${ }^{1}$ Barts Thorax Centre, Barts Health NHS Trust, London, UK ${ }^{2}$ York Health Economics Consortium, Heslington, UK ${ }^{3}$ Medtronic United Kingdom, Watford, UK

${ }^{4}$ Leeds Teaching Hospitals NHS Trust, Leeds, UK

${ }^{5}$ NIHR Respiratory Biomedical Research Unit, Royal Brompton and Harefield NHS Foundation Trust and Imperial College, London, UK

${ }^{6}$ Queen Elizabeth Hospital Birmingham, Birmingham, UK

Correspondence to

Stuart Mealing;

stuart.mealing@york.ac.uk

\section{ABSTRACT}

Introduction Lung cancer is accountable for 35000 deaths annually, and prognosis is improved when the cancer is diagnosed early. CT-guided biopsy (transthoracic needle aspiration, TTNA) and electromagnetic navigation bronchoscopy (ENB) can be used to investigate indeterminate pulmonary nodules if the patient is unfit for surgery. However, there is a paucity of clinical and health economic evidence that directly compares ENB with TTNA in this population group. This cost-effectiveness study aimed to explore potential scenarios whereby ENB may be considered cost-effective when compared with TTNA Methods A cohort decision analytic model was developed using a UK National Health Service perspective. ENB was assumed to have equal sensitivity to TTNA at $82 \%$. Lifetime costs and quality-adjusted life-year (QALY) gain were calculated to estimate the net monetary benefit at a £20000 per QALY threshold. Sensitivity analyses were used to explore scenarios where ENB could be considered a cost-effective intervention.

Results Under the assumption that ENB has equal efficacy to TTNA, ENB was found to be dominant (less costly and more effective) when compared with TTNA, due to having a reduced risk and cost of adverse events. This conclusion was most sensitive to changes in the cost of intervention, estimates of effectiveness and adverse event rates.

Discussion ENB is expected to be cost-effective when the likelihood of an accurate diagnosis is equal to (or better than) TTNA, which may occur in certain subgroups of patients in whom TTNA is unlikely to accurately diagnose malignancy or when an experienced practitioner achieves a high accuracy with ENB.

\section{INTRODUCTION}

Lung cancer is the third most common cancer in the UK and the UK's biggest cancer killer accounting for nearly 50000 new cases per year and over 35000 deaths; more than

\section{Key messages}

Under which circumstances is electromagnetic navigation bronchoscopy (ENB) compared with CT-guided biopsy (transthoracic needle aspiration, TTNA) expected to be cost-effective for the diagnosis of malignant indeterminate peripheral pulmonary nodules?

Health economic decision modelling suggests that ENB is likely to be cost-effective compared with TTNA when equal diagnostic accuracy is assumed, however, in certain scenarios ENB remains costeffective even if TTNA has a higher sensitivity.

Currently, there is uncertainty regarding the extent that the lower risks, costs and clinical harm of adverse events associated with ENB may offset the higher procedural cost of ENB when compared with TTNA to diagnose malignant indeterminate pulmonary nodules; this paper explores the scenarios in which ENB may be considered cost-effective.

breast, bowel, bladder and uterine cancer combined. ${ }^{1}$ There are four stages of lung cancer (I-IV). Cancers diagnosed at the early stages are usually treated with curative intent ${ }^{2}$ and have a significantly better prognosis. ${ }^{3}$

The number of cases diagnosed at early stages is expected to increase as lung cancer screening gains momentum. However, many lung cancer cases first present as indeterminate nodules requiring further investigation before proceeding to definitive treatment. As many as $96.4 \%$ of positive screening results were actually false positives in the National Lung Screening Trial. ${ }^{4}$ Despite the use of nodule algorithms, many nodules still remain indeterminate, presenting a clinical dilemma 


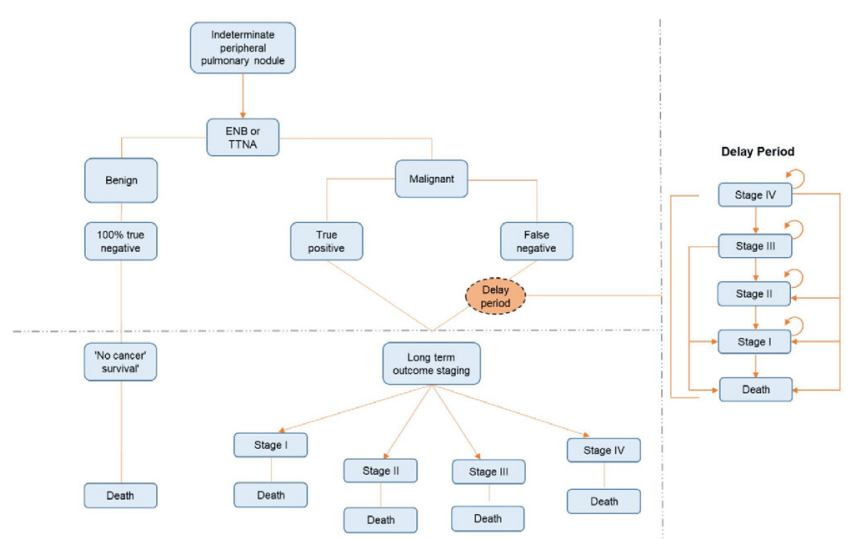

Figure 1 Model structure top panel: schematic of diagnostic decision-tree used in short-term model (top left panel), Delay period (right panel) and long-term outcomes (bottom left panel). ENB, electromagnetic navigation bronchoscopy; TTNA, transthoracic needle aspiration.

as to whether to proceed with surgery for potentially benign disease or attempt to confirm malignancy first by invasive biopsy techniques.

On suspicion of lung cancer, a fluorodeoxyglucosepositron emission tomography scan is undertaken to determine the site with the highest staging significance for example, site of potential metastasis, such as liver, or nodal disease. This site is sampled to confirm malignancy and staging in a single procedure. ${ }^{5}$ For indeterminate pulmonary nodules, especially those too peripheral to be sampled by conventional bronchoscopy, options of further management include CT-guided biopsy (transthoracic needle aspiration (TTNA)), electromagnetic navigation bronchoscopy (ENB) and surgical excision biopsy. These strategies all carry a risk of direct complications, such as surgical and perioperative complications, iatrogenic pneumothorax or haemorrhage, or indirect complications arising from delayed or missed diagnosis. The choice of modality should take into account both diagnostic accuracy and safety ${ }^{6}$ with nodule size and location as well as lung function and the presence, location and degree of emphysema influencing this.

The British Thoracic Society (BTS) guidelines recommend image-guided biopsy for people who may not be fit for surgery and as the first line of investigation for people with indeterminate pulmonary nodules (Herder risk $10 \%-70 \%) .{ }^{6}$ TTNA is considered as standard of care in image-guided biopsy and has been shown to have a high sensitivity ${ }^{6}$ (therefore decreasing the probability of a delayed or missed diagnosis). However, it carries a relatively high likelihood of adverse events such as pneumothorax and pulmonary haemorrhage when compared with less invasive techniques, such as ENB.

ENB is a minimally invasive approach that uses navigation technology to access peripheral areas of the lung. ${ }^{7}$ ENB is a viable option for diagnostic investigation when the location of the pulmonary nodule means alternative diagnostic investigations would result in low diagnostic yield or pose a high risk of complications. There is also a clinical expectation that diagnostic sensitivity of ENB could be similar to TTNA if used routinely.

However, in this high-risk group, there is uncertainty as to whether the lower complication rates with ENB outweigh the higher upfront cost of ENB compared with TTNA. This study presents an exploratory costeffectiveness model comparing ENB with TTNA for the investigation of malignancy in indeterminate peripheral pulmonary nodules under the assumption of equal efficacy of ENB and TTNA in patients who have high risk of direct complications with invasive biopsy.

\section{METHODS \\ Model overview}

The cost-effectiveness model was developed in Microsoft Excel 2013 using a UK National Health Service (NHS) and personal social services perspective and a lifetime horizon. The model comprised a diagnostic decision tree and submodels for the delay period and long-term outcome following a diagnostic result. This is shown in the top left, right and bottom left panels in figure 1, respectively. The model was used to quantify the lifetime costs and benefits (expressed as quality-adjusted life years (QALYs) ) for the population of interest receiving either ENB or TTNA.

Initially, a hypothetical cohort of patients entered the diagnostic decision tree (top left panel, figure 1). The proportion of patients for each diagnostic outcome was calculated using the baseline prevalence of malignancy and the test sensitivity. Further diagnostic tests were not indicated if malignancy was not identified. Costs and health-related quality of life (HRQoL) decrements were applied proportionally to the risk of adverse events associated with the diagnostic modality. The procedural cost of the diagnostic test was applied to all patients.

Patients with benign nodules entered a health state with all-cause mortality estimates applied. Patients found to have malignant nodules entered the long-term outcomes model (bottom left panel, figure 1) at the determined stage of cancer. Progression to the long-term outcomes model was either immediate (following a true positive diagnostic outcome) or after a delay period (following a false negative diagnostic outcome).

Within the delay period, either disease progression or death could occur during the wait to treatment. The outcome of the delay period was calculated by a series of Markov models with a monthly cycle (right panel, figure 1). Movement between health states in the delay period was based on a series of fixed transition probabilities and death was possible from all health states. A 1-month delay to treatment was assumed, with a 6-month delay tested in sensitivity analysis.

The long-term outcomes model consisted of four health states defined by stage of cancer at diagnosis, and death. Movement between health states, once allocated on entry into the long-term model was not possible. The 
survival trajectory of each health state corresponded with that expected for the stage of cancer at diagnosis. ${ }^{8}$ The long-term outcome model had an annual cycle length and a half cycle correction applied to costs and benefits.

Costs and benefits in all three submodels were discounted at $3.5 \%$ per annum in line with the National Institute for Health and Care Excellence reference case. ${ }^{9}$ The model was populated using studies identified through targeted literature searches, and supplemented by clinical opinion. Key model outputs were incremental cost-effectiveness ratios based on the ratio of additional costs and benefits of ENB over TTNA and incremental net monetary benefit (NMB). The latter was calculated using a cost-effectiveness threshold of $£ 20000$ per QALY gained.

\section{Data sources and model parameters}

\section{Population}

The model evaluated a hypothetical cohort of patients with an indeterminate peripheral pulmonary nodule that required further investigation for malignancy. This included patients not suitable for invasive biopsy due to poor lung function (such as people with advanced chronic obstructive pulmonary disorder, emphysema or postsurgical patients). ${ }^{1011}$ The pretest prevalence of malignancy of any severity was assumed to be $40 \%$ (the midpoint of the Herder score that would indicate further investigation $^{6}$ ), the starting age of the population was 70 years old and $50 \%$ were assumed to be male. ${ }^{12}$ Assuming an individual had lung cancer, the distribution of patients across each of the four severity stages used in the model was taken from Folch $e a^{12}$ (see table 1).

\section{Survival and disease progression}

An age and gender-dependent all-cause mortality rate was applied in the long-term outcomes model to the patients with benign nodules. ${ }^{13}$ For people diagnosed with lung cancer, fixed annual probabilities of death, stratified by severity stage, were derived from 5-year survival rates in a large worldwide study (81000 patients from 19 countries) which incorporated any cause of death ${ }^{8}$ (table 1 ). The annual probability of death for non-diagnosed lung cancer was assumed to be the same as for stage I cancer. The monthly probability of prediagnosis disease progression in the delay period was informed by published expert elicitation estimates for limited, advanced and extensive non-small-cell lung carcinoma ${ }^{14}$ (table 1$)$.

\section{Effectiveness}

The difference in sensitivity between ENB and TTNA is uncertain due to a lack of published comparative data regarding the diagnosis of malignant peripheral indeterminate pulmonary nodules. The sensitivity of ENB reported by studies included in a meta-analysis evaluating diagnosis of peripheral lung nodules was $50 \%-100 \% .^{15}$ The sensitivity of TTNA quoted by studies considered in the BTS guideline for the diagnosis of malignant indeterminate nodules (but not necessarily peripheral) ranged from $77 \%$ to $97 \% .{ }^{6}$ For the purposes of this exploratory model, the sensitivity of TTNA and ENB was assumed to be equivalent at $82 \%$, the mean from the ENB meta-analysis. ${ }^{15}$

The relative accuracy between diagnostic modalities is highly uncertain, and therefore effectiveness values were subject to sensitivity analysis. Specificity was assumed to be $100 \%$; with no false positive results given malignancy would only be identified if present.

\section{Diagnostic intervention-related adverse events}

Iatrogenic pneumothorax and pulmonary haemorrhage were the two key diagnostic intervention-related adverse events considered within the model. Clinically significant haemorrhage and pneumothorax requiring hospitalisation were associated with a cost and disutility. The likelihood and cost of pneumothorax was refined by whether or not an intervention was required within the hospital stay. The values used in the model for ENB and TTNA were taken from publications by Folch $e t a l^{12}$ and DiBardino et al, ${ }^{16}$ respectively (table 1 ).

\section{Health-related quality of life (HRQoL)}

Health state preference values (utilities) were assigned to each health state in the model (including sub-models). These values conventionally range from 0 to 1 , with 1 corresponding to perfect health and 0 to death. Based on information presented in a UK-specific HRQoL study by Sturza $e a^{17}$ the values used in the model for stages I/II, III and IV were assumed to correspond to the published values for non-metastatic, mixed/not specified and metastatic lung cancer, respectively (table 1 ). The utilities applied within the model were age adjusted with a relative decrement derived from the HRQoL expected for people without malignancy and population norms. ${ }^{18} 19$ Each year survived in the long-term outcomes model was weighted by the relevant utility value to estimate the QALY gain. The model applied a utility decrement for each of the two adverse events, calculated by applying the associated disutility of the event ${ }^{20}$ over an assumed 2-month period (table 1 ).

\section{Resources and costs}

Resources and costs associated with the implementation of the interventions, management of adverse events and delayed diagnosis, as well as the long-term management of the different stages of cancer were taken into account (table 1). Wherever possible, costs were identified from publicly available sources and list prices ${ }^{21-23}$ and, where applicable, inflated to 2017-2018 (the cost year of the analysis) using the HCHS index. ${ }^{21}$ The estimated cost of ENB was derived through a micro costing (with summarised costs presented in table 2). The resource use for this costing was derived from unstructured interviews and observations at a London tertiary hospital (personal communication, Medtronic) in 2016/2017, with costs inflated to the year of the analysis. The cost of ENB is 
Table 1 List of key parameter values and sources

\begin{tabular}{lcc}
\hline Input & Value in model & Source/notes \\
\hline & Proportion of presenting cohort by stage of lung cancer \\
Stage I & $54 \%$ & Folch et al $^{12}$ \\
Stage II & $11 \%$ & \\
Stage III & $17 \%$ & \\
Stage IV & $18 \%$ & Survival and disease progression
\end{tabular}

\begin{tabular}{lcc} 
All-cause mortality & Various & Age and sex adjusted, ONS \\
\hline Annual probability of death with treatment (by stage at diagnosis) & \\
Stage I & 0.1032 & Derived from information in Cancer Research UK \\
Stage II & 0.1857 & $(2014)^{8}$ \\
Stage III & 0.3180 & \\
Stage IV & 0.4043 &
\end{tabular}

\section{Monthly probability of disease progression without treatment}

$\begin{array}{lll}\text { Stage I and II to stage III } & 0.05 & \text { Informed by information in Hinde et al } \\ \text { Stage I and II to stage IV } & 0.10 & \\ \text { Stage III to IV } & 0.20 & \\ \text { Death } & 0.01 & \text { Assumed to have the same survival as patients with } \\ & & \text { stage I cancer. Cancer Research UK (2014) }\end{array}$

\section{Probability of adverse events}

\begin{tabular}{|c|c|c|}
\hline $\begin{array}{l}\text { ENB-related pneumothorax (requiring } \\
\text { intervention) }\end{array}$ & $2.88 \%$ & Folch et $a l^{12}$ \\
\hline $\begin{array}{l}\text { ENB-related pneumothorax (not } \\
\text { requiring intervention) }\end{array}$ & $1.40 \%$ & \\
\hline ENB pulmonary haemorrhage & $1.48 \%$ & \\
\hline $\begin{array}{l}\text { TTNA-related pneumothorax (requiring } \\
\text { intervention) }\end{array}$ & $7.28 \%$ & DiBardino et $a l^{16}$ \\
\hline $\begin{array}{l}\text { TTNA-related pneumothorax (not } \\
\text { requiring intervention) }\end{array}$ & $13.20 \%$ & \\
\hline TTNA pulmonary haemorrhage & $2.73 \%$ & \\
\hline \multicolumn{3}{|c|}{ HRQoL* } \\
\hline No cancer utility & 0.855 & Szende et $a l^{18}$ \\
\hline Stage I utility & 0.825 & $\begin{array}{l}\text { Based on the pooled estimate of non-metastatic } \\
\text { NSCLC, Sturza }{ }^{17}\end{array}$ \\
\hline Stage II utility & 0.825 & Assumed equivalent to stage I cancer. Sturza ${ }^{17}$ \\
\hline Stage III utility & 0.772 & $\begin{array}{l}\text { Based on the pooled estimate of mixed/not } \\
\text { specified NSCLC. Sturza }(2010)^{17}\end{array}$ \\
\hline Stage IV utility & 0.537 & $\begin{array}{l}\text { Based on the pooled estimate of metastatic } \\
\text { NSCLC. Sturza (2010) }{ }^{17}\end{array}$ \\
\hline Relative decrement for age & 0.912 & $\begin{array}{l}\text { Based on utility value of } 0.78 \text { for a } 70 \text { year old. Kind } \\
\text { et al }(1999)^{19}\end{array}$ \\
\hline Disutility of pneumothorax & -0.1388 & \multirow{2}{*}{$\begin{array}{l}\mathrm{SMDM}^{29} \text {. Disutility applied for a 2-month duration } \\
\text { (assumed) }\end{array}$} \\
\hline Disutility of haemorrhage & -0.0821 & \\
\hline
\end{tabular}

Costs

\section{Intervention procedural costs}

ENB £1942 Estimated via a micro costing (see table 2)


Table 1 Continued

\begin{tabular}{lll}
\hline Input & Value in model & Source/notes \\
\hline TTNA & $£ 1630$ & Calculated by adding the costs of the image- \\
& & guided biopsy of lesion muscle of connective tissue \\
& & $(£ 1481)$ (Total HRG code: YH32A) and the cost of \\
& & the full pulmonary function testing (£150) (Total \\
& HRG code: DZ52Z)
\end{tabular}

\begin{tabular}{|c|c|c|}
\hline \multicolumn{3}{|l|}{ Adverse event costs } \\
\hline Haemorrhage & $£ 3127$ & $\begin{array}{l}\text { Assumed equivalent to non-elective tracheostomy } \\
\text { code: } C A 63 Z^{22}\end{array}$ \\
\hline \multicolumn{3}{|c|}{ Cost of false negative (delayed diagnosis) } \\
\hline Cost of CT scan & $£ 106$ & $\begin{array}{l}\text { CT scan of two areas, with contrast. Code: } \\
\text { RD } 24 Z^{22}\end{array}$ \\
\hline Cost of GP appointment & $£ 37$ & PSSRU $2018^{21}$ \\
\hline Stage III non-resected cancer & $£ 9078(£ 8733)$ & \\
\hline Stage IV non-resected cancer & $£ 13595(£ 13078)$ & \\
\hline
\end{tabular}

*Please note utilities were age adjusted throughout the lifetime of the cohort.

ENB, electromagnetic navigation bronchoscopy; HRQoL, health-related quality of life; NSCLC, non-small-cell lung carcinoma; ONS, Office for National Statistics; TTNA, transthoracic needle aspiration.

dependent first on the running costs of the bronchoscopy suite, radiology department or operating theatre and second on the proportion of procedures which are undertaken under general anaesthetic. Both of these parameters were subject to sensitivity analysis.

\section{Uncertainty analysis}

In this exploratory model, deterministic sensitivity analysis was undertaken to evaluate the impact of uncertainty of input values on the conclusions. In these analyses, a positive value of NMB corresponds to ENB being costeffective. One-way (where input parameters were varied one by one between plausible extremes) sensitivity was carried out on the adverse event rates and two-way (where more than one parameter is varied at the same time) sensitivity analyses were undertaken on the sensitivity values for ENB and TTNA and the ENB costs. In addition, analyses were rerun with a higher sensitivity of $92 \%$, taken from a meta-analysis of diagnostic accuracy for TTNA ${ }^{16}$ to explore the thresholds at which ENB could be cost-effective if diagnostic effectiveness was not equal.

\section{RESULTS}

The summary results of this early exploratory costeffectiveness model are presented in table 3 . Under the assumption of equal efficacy and that ENB can be undertaken in a bronchoscopy suite/radiology department with no need for general anaesthetic, ENB was found to be dominant (less costly and more effective) when compared with TTNA due to having a reduced risk and cost of adverse events (which offset the higher intervention cost of ENB).

\section{Uncertainty analysis}

One-way sensitivity analysis demonstrated that under the assumption of equal efficacy, the results were sensitive to the accuracy and cost of both diagnostic procedures, and the risk of TTNA-related adverse events. Changing the pretest prevalence of malignancy between $10 \%$ and $70 \%$ did not have sufficient impact to change conclusions.

The impact of different combinations of sensitivity values for ENB and TTNA on cost-effectiveness was evaluated in a two-way sensitivity analysis. The results in table 4 show that ENB can be up to $8 \%$ less sensitive than TTNA and remain cost-effective. With a 6-month delay to treatment after a false negative result, ENB can be up to $2 \%$ less sensitive than TTNA and remain cost-effective.

Two-way sensitivity analyses were also undertaken for trade-offs between ENB sensitivity and ENB cost. ENB is cost-effective under the assumption of equal effectiveness 
Table 2 Items and costs included within the ENB costing scenarios

\begin{tabular}{|c|c|c|c|}
\hline Input & $\begin{array}{l}\text { Value used } \\
\text { in model }\end{array}$ & $\begin{array}{l}\text { Upper } \\
\text { estimate }\end{array}$ & Notes \\
\hline $\begin{array}{l}\text { Costs of } \\
\text { superDimension device } \\
\text { for ENB }\end{array}$ & $£ 1103$ & & $\begin{array}{l}\text { Average of three separate strategies (personal communication, } \\
\text { Medtronic): } \\
\text { Dx strategy } 1=£ 1026 \\
\text { Dx strategy } 2=£ 1119 \\
\text { Marker insertion }=£ 1094\end{array}$ \\
\hline $\begin{array}{l}\text { Cost of running } \\
\text { operating room }\end{array}$ & $£ 153$ & $£ 537$ & $\begin{array}{l}25 \min X £ 6 \text { per minute (personal communication, Medtronic) } \\
25 \min X £ 21 \text { per minute (personal communication, Medtronic) }\end{array}$ \\
\hline Staff time & $£ 566$ & & $\begin{array}{l}\text { Subtotal for: } 25 \text { min for medical consultant, operating department } \\
\text { practitioner (band 5) and scrub nurse (band 6); } 30 \text { min for recovery } \\
\text { nurse (band 5); } 75 \text { min for anaesthetist ( } 75 \mathrm{~min})^{21}\end{array}$ \\
\hline $\begin{array}{l}\text { Proportion of } \\
\text { procedures under GA }\end{array}$ & $0 \%$ & $81.40 \%{ }^{12}$ & \\
\hline Drugs-GA & $£ 0$ & $£ 24$ & $\begin{array}{l}\text { Weighted subtotal according to proportion of procedures under GA } \\
\text { (unweighted subtotal £29.87) }\end{array}$ \\
\hline Drugs - sedation & $£ 12$ & $£ 2$ & $\begin{array}{l}\text { Weighted subtotal according to proportion of procedures under GA } \\
\text { (unweighted subtotal }=£ 11.77)^{23}\end{array}$ \\
\hline Consumables & $£ 11$ & & $\begin{array}{l}\text { Includes: } 2 \text { suction tubes, } 220 \mathrm{~mL} \text { syringe, Green hypo, } 100 \mathrm{~mL} \text { N/ } \\
\text { saline bag, gallipot, sputum pot, } 3 \text { small specimen bottles, long thin } \\
\text { endoscopic sucker (personal communication, Medtronic) }\end{array}$ \\
\hline $\begin{array}{l}\text { Anaesthetic } \\
\text { consumables }\end{array}$ & $£ 5$ & & $\begin{array}{l}\text { Includes: cannula, drip, seven syringes (personal communication, } \\
\text { Medtronic) }\end{array}$ \\
\hline Tests & $£ 13$ & & Includes FBC, blood clot test, platelet count, INR and IPT 22 \\
\hline Total & $£ 1863$ & $£ 2226$ & \\
\hline
\end{tabular}

Note, where applicable costs were inflated to the $2017 / 2018$ cost year using the HCHS index. Cost of device provided by Medtronic, with cost of the operating room and related consumables based on data collected at tertiary London hospital in 2016 (personal communication, Medtronic).

ENB, electromagnetic navigation bronchoscopy; FBC, full blood count; GA, general anaesthesia; HCHS, Hospital and Community Health Services; INC, international normalised ratio; IPT, immune thrombocytopenia.

(82\%) with TTNA if ENB costs approximately £2000 or less (table 5). For ENB to achieve this cost, the operating theatre cost needs to be lower than $£ 11$ per minute and fewer than $50 \%$ of ENB procedures undertaken with general anaesthetic (table 6). Anecdotally it is likely that the majority of ENB is currently being undertaken under general anaesthetic, but with increasing operator experience and improving accuracy of the system the numbers being performed without general anaesthetic are increasing.

Table 7 shows that if the sensitivity of TTNA is $92 \%$, and ENB is at $82 \%$, then assuming a 1-month delay ENB would need to cost approximately $£ 1800$ or less to be cost-effective (ie, an additional saving of $£ 200$ is needed to offset the shortfall in efficacy, tables 5 and 7). If a 6-month delay to diagnosis is expected after a false negative, ENB would need to cost approximately $£ 1300$ or less (ie, an additional saving of $£ 700$ is required to offset the shortfall in efficacy).

Figure 2 illustrates the impact that changing the likelihood of adverse events has on the incremental benefit via a one-way sensitivity analysis. Assuming equal diagnostic efficacy of $82 \%$ and all else held constant, for ENB to be cost-effective the likelihood of pneumothorax requiring intervention needs to be below 7\% with ENB and above $3 \%$ with TTNA. This finding remained constant when delay to diagnosis following a false negative was increased to 6 months.

If the sensitivity of TTNA increases to $92 \%$, all else held constant, then the TTNA probabilities of pneumothorax requiring intervention and haemorrhage need to be at least $8 \%$ and $4 \%$, respectively for ENB to be cost-effective in comparison. If the delay to diagnosis was increased to 6 months following a false negative, these probabilities of adverse events increase to $21 \%$ and $18 \%$ respectively.

\section{DISCUSSION}

The model aimed to explore the potential key drivers of the cost-effectiveness of ENB compared with TTNA, the current standard of care. The primary conclusion from our analysis is that ENB is likely cost-effective when the likelihood of an accurate diagnosis is equal to (or better than) TTNA. This may occur in certain subgroups of patients whom TTNA is unlikely to accurately diagnose malignancy or when an experienced practitioner achieves a high accuracy with ENB. 
Table 3 Results (per patient) assuming equal sensitivity of ENB and TTNA

\begin{tabular}{llll}
\hline $\begin{array}{l}\text { Economic } \\
\text { outcome }\end{array}$ & ENB & TTNA & Incremental \\
\hline $\begin{array}{l}\text { Diagnostic } \\
\text { strategy cost }\end{array}$ & $£ 1863$ & $£ 1630$ & $£ 232$ \\
$\begin{array}{l}\text { Cancer treatment } \\
\text { cost }\end{array}$ & $£ 17677$ & $£ 17677$ & $£ 0$ \\
$\begin{array}{l}\text { Cost of delayed } \\
\text { diagnosis }\end{array}$ & $£ 10$ & $£ 10$ & $£ 0$ \\
$\begin{array}{l}\text { Cost of adverse } \\
\text { events }\end{array}$ & $£ 149$ & $£ 469$ & $-£ 320$ \\
$\begin{array}{l}\text { Total cost per } \\
\text { patient }\end{array}$ & $£ 19698$ & $£ 19786$ & $-£ 88$ \\
$\begin{array}{l}\text { QALYs } \\
\text { Disutility }\end{array}$ & -0.45048 & 6.45048 & 0.000000 \\
\hline $\begin{array}{l}\text { Total QALY per } \\
\text { patient }\end{array}$ & 6.44962 & -0.00349 & 0.00263 \\
\hline $\begin{array}{ll}\text { ICER } \\
\text { Incremental NMB }\end{array}$ & 6.44699 & 0.00263 \\
\hline
\end{tabular}

ENB, electromagnetic navigation bronchoscopy; ICER,

Incremental cost-effectiveness ratio; NMB, net monetary benefit;

QALYs, quality-adjusted life-years; TTNA, transthoracic needle aspiration.

However, findings in the main analysis (table 3 ) need to be interpreted with caution given that the relative accuracy of the tests was assumed to be equal. If TTNA is parametrised with $92 \%$ accuracy (rather than $82 \%$ accuracy),
ENB would have to be either (1) no less than $84 \%$ accurate, or (2) cost under $£ 1800$ (assuming $82 \%$ sensitivity of ENB) to be cost-effective (see table 7). Alternatively, if the rates of pneumothorax requiring intervention or pulmonary haemorrhage with TTNA were at least $8 \%$ and $4 \%$, respectively, ENB would be cost-effective (even when TTNA had a $92 \%$ sensitivity vs an ENB sensitivity of $82 \%$ ).

\section{Lack of comparative data which is applicable to the population of interest}

There is currently a lack of robust comparative evidence between ENB and standard of care in the population of interest. In previous studies, differences in baseline characteristics of study populations (such as stage of cancer and location of lesions) and differences in observable and unobservable effect modifiers when synthesising diagnostic evidence, has hindered robust comparative analysis of different diagnostics. ${ }^{24}$ ENB is likely to be most suitable for patients with peripheral nodules and those at high risk of diagnostic complications. Considering this, it is unclear if the higher estimates of sensitivity for TTNA (ie, often above $90 \%{ }^{6}{ }^{16}$ ) are applicable to the population who may most benefit from ENB. A small case study $(\mathrm{n}=108)$ found that while TTNA sensitivity to diagnose central samples was $76 \%$, sensitivity was less than $69 \%$ in regard to peripheral samples. ${ }^{25}$ However, the NAVIGATE study ${ }^{12}$ estimated an ENB sensitivity of $69 \%$, which is only comparable to the lower estimates of TTNA and ENB sensitivity. ${ }^{15}$ While NAVIGATE evaluated ENB in the

Table 4 Two-way sensitivity analysis for the effectiveness of ENB and TTNA

\begin{tabular}{|c|c|c|c|c|c|c|c|c|c|c|c|c|c|c|}
\hline & & \multicolumn{13}{|c|}{ ENB sensitivity } \\
\hline & & $80 \%$ & $81 \%$ & $82 \%$ & $83 \%$ & $84 \%$ & $85 \%$ & $86 \%$ & $87 \%$ & $88 \%$ & $89 \%$ & $90 \%$ & $91 \%$ & $92 \%$ \\
\hline \multirow[t]{16}{*}{ TTNA sensitivity } & $85 \%$ & $£ 55$ & $£ 72$ & $£ 89$ & $£ 106$ & $£ 123$ & $£ 140$ & $£ 158$ & $£ 175$ & $£ 192$ & $£ 209$ & $£ 226$ & $£ 243$ & $£ 261$ \\
\hline & $86 \%$ & $£ 37$ & $£ 55$ & $£ 72$ & $£ 89$ & $£ 106$ & $£ 123$ & $£ 140$ & $£ 158$ & $£ 175$ & $£ 192$ & $£ 209$ & $£ 226$ & $£ 243$ \\
\hline & $87 \%$ & $£ 20$ & $£ 37$ & $£ 55$ & $£ 72$ & $£ 89$ & $£ 106$ & $£ 123$ & $£ 140$ & $£ 158$ & $£ 175$ & $£ 192$ & $£ 209$ & $£ 226$ \\
\hline & $88 \%$ & $£ 3$ & $£ 20$ & $£ 37$ & $£ 55$ & $£ 72$ & $£ 89$ & $£ 106$ & $£ 123$ & $£ 140$ & $£ 158$ & $£ 175$ & $£ 192$ & $£ 209$ \\
\hline & $89 \%$ & $-£ 14$ & $£ 3$ & $£ 20$ & $£ 37$ & $£ 55$ & $£ 72$ & $£ 89$ & $£ 106$ & $£ 123$ & $£ 140$ & $£ 158$ & $£ 175$ & $£ 192$ \\
\hline & $90 \%$ & $-£ 31$ & $-£ 14$ & $£ 3$ & $£ 20$ & $£ 37$ & $£ 55$ & $£ 72$ & $£ 89$ & $£ 106$ & $£ 123$ & $£ 140$ & $£ 158$ & $£ 175$ \\
\hline & $91 \%$ & $-£ 48$ & $-£ 31$ & $-£ 14$ & $£ 3$ & $£ 20$ & $£ 37$ & $£ 55$ & $£ 72$ & $£ 89$ & $£ 106$ & $£ 123$ & $£ 140$ & $£ 158$ \\
\hline & $92 \%$ & $-£ 65$ & $-£ 48$ & $-£ 31$ & $-£ 14$ & $£ 3$ & $£ 20$ & $£ 37$ & $£ 55$ & $£ 72$ & $£ 89$ & $£ 106$ & $£ 123$ & $£ 140$ \\
\hline & $93 \%$ & $-£ 83$ & $-£ 65$ & $-£ 48$ & $-£ 31$ & $-£ 14$ & $£ 3$ & $£ 20$ & $£ 37$ & $£ 55$ & $£ 72$ & $£ 89$ & $£ 106$ & $£ 123$ \\
\hline & $94 \%$ & $-£ 100$ & $-£ 83$ & $-£ 65$ & $-£ 48$ & $-£ 31$ & $-£ 14$ & $£ 3$ & $£ 20$ & $£ 37$ & $£ 55$ & $£ 72$ & $£ 89$ & $£ 106$ \\
\hline & $95 \%$ & $-£ 117$ & $-£ 100$ & $-£ 83$ & $-£ 65$ & $-£ 48$ & $-£ 31$ & $-£ 14$ & $£ 3$ & $£ 20$ & $£ 37$ & $£ 55$ & $£ 72$ & $£ 89$ \\
\hline & $96 \%$ & $-£ 134$ & $-£ 117$ & $-£ 100$ & $-£ 83$ & $-£ 65$ & $-£ 48$ & $-£ 31$ & $-£ 14$ & $£ 3$ & $£ 20$ & $£ 37$ & $£ 55$ & $£ 72$ \\
\hline & $97 \%$ & $-£ 151$ & $-£ 134$ & $-£ 117$ & $-£ 100$ & $-£ 83$ & $-£ 65$ & $-£ 48$ & $-£ 31$ & $-£ 14$ & $£ 3$ & $£ 20$ & $£ 37$ & $£ 55$ \\
\hline & $98 \%$ & $-£ 168$ & $-£ 151$ & $-£ 134$ & $-£ 117$ & $-£ 100$ & $-£ 83$ & $-£ 65$ & $-£ 48$ & $-£ 31$ & $-£ 14$ & $£ 3$ & $£ 20$ & $£ 37$ \\
\hline & $99 \%$ & $-£ 186$ & $-£ 168$ & $-£ 151$ & $-£ 134$ & $-£ 117$ & $-£ 100$ & $-£ 83$ & $-£ 65$ & $-£ 48$ & $-£ 31$ & $-£ 14$ & $£ 3$ & $£ 20$ \\
\hline & $100 \%$ & $-£ 203$ & $-£ 186$ & $-£ 168$ & $-£ 151$ & $-£ 134$ & $-£ 117$ & $-£ 100$ & $-£ 83$ & $-£ 65$ & $-£ 48$ & $-£ 31$ & $-£ 14$ & $£ 3$ \\
\hline
\end{tabular}

Results presented are for NMB at $£ 20000$ threshold.

ENB, electromagnetic navigation bronchoscopy; NMB, net monetary benefit; TTNA, transthoracic needle aspiration. 
Table 5 Two-way sensitivity analysis for the cost and effectiveness of ENB

\begin{tabular}{|c|c|c|c|c|c|c|c|c|c|c|c|c|c|}
\hline & & \multicolumn{12}{|c|}{ ENB sensitivity } \\
\hline & & $50 \%$ & $60 \%$ & $65 \%$ & $70 \%$ & $75 \%$ & $80 \%$ & $82 \%$ & $85 \%$ & $90 \%$ & $92 \%$ & $95 \%$ & $100 \%$ \\
\hline \multirow[t]{12}{*}{ ENB cost } & $£ 1000$ & $£ 454$ & $£ 626$ & $£ 711$ & $£ 797$ & $£ 883$ & $£ 969$ & $£ 1003$ & $£ 1054$ & $£ 1140$ & $£ 1175$ & $£ 1226$ & $£ 1312$ \\
\hline & $£ 1250$ & $£ 204$ & $£ 376$ & $£ 461$ & $£ 547$ & $£ 633$ & $£ 719$ & $£ 753$ & $£ 804$ & $£ 890$ & $£ 925$ & $£ 976$ & $£ 1062$ \\
\hline & $£ 1500$ & $-£ 46$ & $£ 126$ & $£ 211$ & $£ 297$ & $£ 383$ & $£ 469$ & $£ 503$ & $£ 554$ & $£ 640$ & $£ 675$ & $£ 726$ & $£ 812$ \\
\hline & $£ 1600$ & $-£ 146$ & $£ 26$ & $£ 111$ & $£ 197$ & $£ 283$ & $£ 369$ & $£ 403$ & $£ 454$ & $£ 540$ & $£ 575$ & $£ 626$ & $£ 712$ \\
\hline & $£ 1700$ & $-£ 246$ & $-£ 74$ & $£ 11$ & $£ 97$ & $£ 183$ & $£ 269$ & $£ 303$ & $£ 354$ & $£ 440$ & $£ 475$ & $£ 526$ & $£ 612$ \\
\hline & $£ 1800$ & $-£ 346$ & $-£ 174$ & $-£ 89$ & $-£ 3$ & $£ 83$ & $£ 169$ & $£ 203$ & $£ 254$ & $£ 340$ & $£ 375$ & $£ 426$ & $£ 512$ \\
\hline & $£ 1900$ & $-£ 446$ & $-£ 274$ & $-£ 189$ & $-£ 103$ & $-£ 17$ & $£ 69$ & $£ 103$ & $£ 154$ & $£ 240$ & $£ 275$ & $£ 326$ & $£ 412$ \\
\hline & $£ 2000$ & $-£ 546$ & $-£ 374$ & $-£ 289$ & $-£ 203$ & $-£ 117$ & $-£ 31$ & $£ 3$ & $£ 54$ & $£ 140$ & $£ 175$ & $£ 226$ & $£ 312$ \\
\hline & $£ 2100$ & $-£ 646$ & $-£ 474$ & $-£ 389$ & $-£ 303$ & $-£ 217$ & $-£ 131$ & $-£ 97$ & $-£ 46$ & $£ 40$ & $£ 75$ & $£ 126$ & $£ 212$ \\
\hline & $£ 2200$ & $-£ 746$ & $-£ 574$ & $-£ 489$ & $-£ 403$ & $-£ 317$ & $-£ 231$ & $-£ 197$ & $-£ 146$ & $-£ 60$ & $-£ 25$ & $£ 26$ & $£ 112$ \\
\hline & $£ 2300$ & $-£ 846$ & $-£ 674$ & $-£ 589$ & $-£ 503$ & $-£ 417$ & $-£ 331$ & $-£ 297$ & $-£ 246$ & $-£ 160$ & $-£ 125$ & $-£ 74$ & $£ 12$ \\
\hline & $£ 2400$ & $-£ 946$ & $-£ 774$ & $-£ 689$ & $-£ 603$ & $-£ 517$ & $-£ 431$ & $-£ 397$ & $-£ 346$ & $-£ 260$ & -£225 & $-£ 174$ & $-£ 88$ \\
\hline
\end{tabular}

Results presented are for NMB at $£ 20000$ threshold, assuming TTNA sensitivity of $82 \%$ sensitivity.

ENB, electromagnetic navigation bronchoscopy; NMB, net monetary benefit; TTNA, transthoracic needle aspiration.

population of interest, the primary outcome measure was safety. Linear or radial endobronchial ultrasound could be used at physician discretion prior or as a complement to $\mathrm{ENB}$, and the pragmatic study design allowed for physician judgement in patient selection ${ }^{12}$; meaning the population selected for ENB may differ from that typically evaluated in TTNA accuracy studies.

The range of sensitivities reported in the literature for ENB may result from heterogeneity between study populations, variations of technique and technology, as well as variation in the reference test. Such limitations and methodological constraints are unlikely to be resolved easily. However, the model results are presented for a range of possible accuracy estimates, and therefore are helpful in understanding potential thresholds at which an intervention may be viewed as cost-effective in the absence of definitive evidence.

\section{Adverse events}

TTNA-related pneumothorax plays an important role in the overall cost of TTNA and the expected cost-effectiveness of ENB. The probability used for TTNArelated pneumothorax that required treatment $(7.28 \%)$ is likely conservative. For example, the model developed by Dale $e t a t^{26}$ used an estimate of $15 \%$, and a more recent study by Boskovic et $a l^{27}$ reported a slightly higher rate of $20 \%$. Abdullah $e t a l^{28}$ also reported the risk of pneumothorax from CT-guided biopsy in a UK setting at $25 \%$ for patients with diminished lung capacity (a forced expiratory volume in one second less than $1 \mathrm{~L}$ ) and $41.5 \%$ in patients with poor inspired oxygen transfer (a transfer factor for carbon monoxide less than $<40 \%) .{ }^{28}$ As shown in the one-way sensitivity analysis (figure 2), ENB is expected to be cost-effective when the risk of clinically significant pneumothorax with TTNA is higher than $10 \%$. As such, ENB is likely to be cost-effective in patients at high risk of complications, even when the ENB has a lower accuracy than TTNA.

\section{Cross-validity with other existing models}

A lack of published models for this indication, as well as the lack of comparative trials of ENB against standard

Table 6 Two-way sensitivity analysis for the cost of theatre operation and proportion of people requiring general anaesthetic for ENB

\begin{tabular}{|c|c|c|c|c|c|c|c|c|c|c|c|c|}
\hline & & \multicolumn{11}{|c|}{ Percentage of people requiring anaesthetic } \\
\hline & & 0 & 10 & 20 & 30 & 40 & 50 & 60 & 70 & 80 & 90 & 100 \\
\hline \multirow{5}{*}{$\begin{array}{l}\text { Cost of } \\
\text { procedure } \\
\text { room (per } \\
\text { minute) }\end{array}$} & $£ 6$ & $£ 140$ & $£ 137$ & $£ 134$ & $£ 131$ & $£ 128$ & $£ 125$ & $£ 122$ & $£ 119$ & $£ 116$ & $£ 113$ & $£ 110$ \\
\hline & $£ 10$ & $£ 38$ & $£ 35$ & $£ 32$ & $£ 29$ & $£ 26$ & $£ 23$ & $£ 20$ & $£ 17$ & $£ 14$ & $£ 11$ & $£ 8$ \\
\hline & $£ 11$ & $£ 13$ & $£ 10$ & $£ 7$ & $£ 4$ & $£ 1$ & $-£ 2$ & $-£ 5$ & $-£ 8$ & $-£ 11$ & $-£ 14$ & $-£ 17$ \\
\hline & $£ 12$ & $-£ 13$ & $-£ 16$ & $-£ 19$ & $-£ 22$ & $-£ 25$ & $-£ 28$ & $-£ 31$ & $-£ 34$ & $-£ 37$ & $-£ 40$ & $-£ 43$ \\
\hline & $£ 21$ & $-£ 243$ & $-£ 246$ & $-£ 249$ & $-£ 252$ & $-£ 255$ & $-£ 258$ & $-£ 261$ & $-£ 264$ & $-£ 267$ & $-£ 270$ & $-£ 273$ \\
\hline
\end{tabular}

Results presented are for NMB using a $£ 20000$ threshold.

NMB, net monetary benefit. 
Table 7 Two-way sensitivity analysis for the cost and effectiveness of ENB

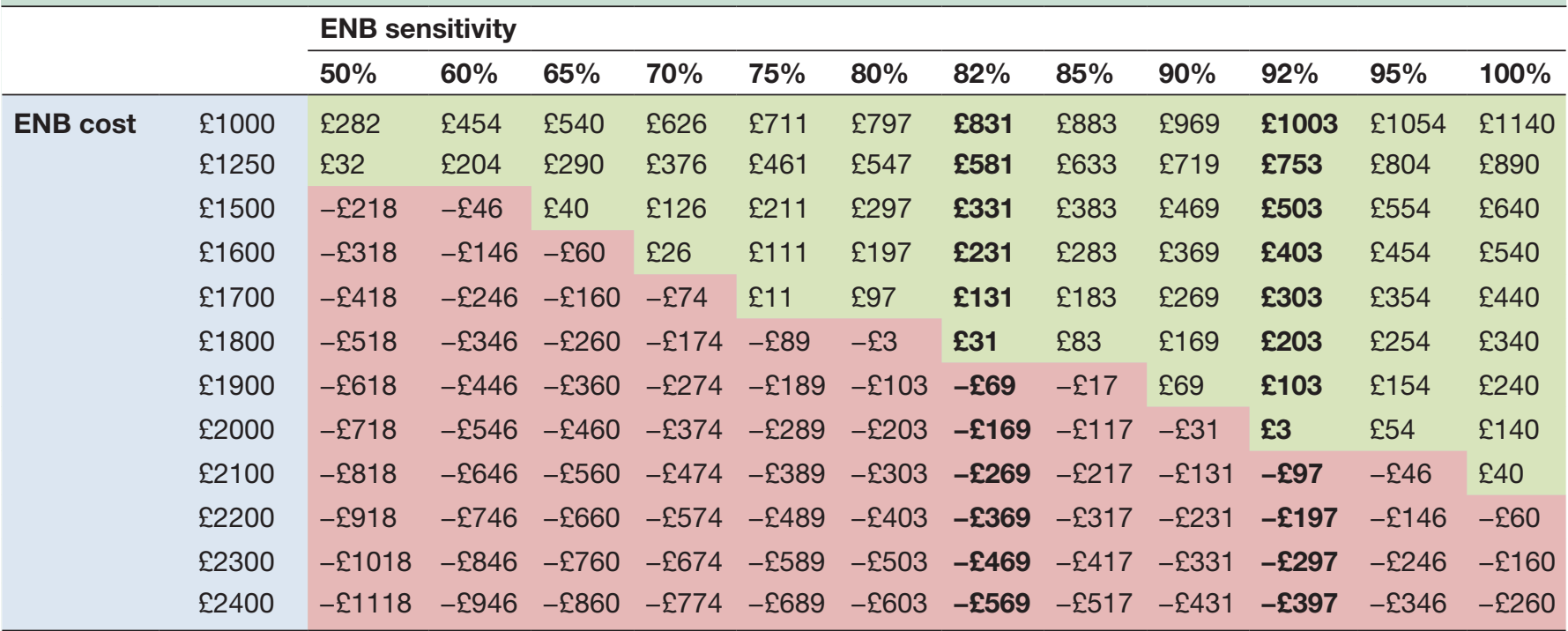

Results presented are for NMB at $£ 20000$ threshold, assuming TTNA sensitivity of $92 \%$

ENB, electromagnetic navigation bronchoscopy; NMB, net monetary benefit; TTNA, transthoracic needle aspiration.

care, means that robust external validation of the model is difficult to achieve. Dale et al developed a decision tree model which compared CT-guided biopsy with navigational bronchoscopy for the diagnosis of solitary pulmonary nodules, using a respective sensitivity of $90 \%$ and $70 \% .{ }^{26}$ Under the assumption that the incremental QALY gain would be minimal, HRQoL was not incorporated. Dale et al found navigational bronchoscopy with biopsy cost more per case, with the cost per diagnosis most sensitive to a change in sensitivity of CT-guided biopsy. However, this model focused on sequential diagnostic

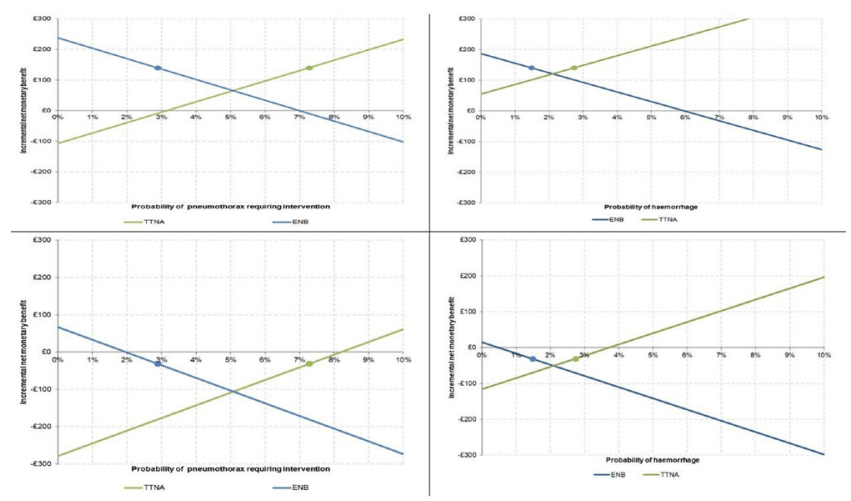

Figure 2 One-way sensitivity analysis regarding adverse events. Panel A (top left): varying the probability of pneumothorax requiring intervention (equal efficacy). Panel B (top right): varying the probability of pulmonary haemorrhage (equal efficacy). Panel C (bottom left): varying the probability of pneumothorax requiring intervention (TTNA sensitivity=92\%). Panel D (bottom right): varying the probability of pulmonary haemorrhage (TTNA sensitivity=92\%). Mean NMB for base case analysis is indicated by a circle for each intervention. ENB,electromagnetic navigation bronchoscopy; NMB, net monetary benefit; TTNA, transthoracic needle aspiration. pathways for a mixed patient population group and adopted a societal perspective. These aspects differ from the model presented herein, preventing direct comparison of results.

\section{Uncaptured benefits and costs}

A key consideration when interpreting results of the study is that benefits beyond the diagnosis of malignancy were not captured. Both TTNA and ENB have high reported diagnostic yields ${ }^{6}$ and could bring additional benefit (which has not been explicitly modelled) in obtaining samples for microbiological diagnosis, undertaking lung lesion biopsy, fiducial marker placement, pleural dye marking or lymph node biopsy within the same ENB procedure. Furthermore, new technological developments may mean isolated diagnostic investigations could be superseded by test and treat strategies, such as navigational bronchoscopy and ablation within one procedure. The potential for ENB to be multipurpose or combined with other procedures was not a focus of this model, however, future evaluations may consider ENB as a means to reduce overall cost by avoidance of a second procedure that may require anaesthetic.

In addition, the overall cost-effectiveness of ENB in comparison to standard care may improve if future routine adoption of ENB led to an increased number of skilled practitioners, potentially leading to improved sensitivity and safety of ENB, as well as a reduced need for general anaesthetic or an operating theatre (two drivers of the cost of ENB).

\section{CONCLUSION}

The applicability and quality of the data informing the model is limited due to a lack of comparative studies in the population of interest. Nonetheless, all inputs were 
subject to clinical validation and sensitivity analysis. The pathway and costing perspective has high applicability to the NHS context. Beyond effectiveness and procedural cost parameters that depend on the service context (ie, practitioner experience or running cost) and population characteristics, all other inputs that relied on expert clinical opinion did not have a large effect on the results and did not change the direction of the results.

Acknowledgements The authors would like to acknowledge the work of Alexandra Filby, Ayeda Nadeem and Catherine Bowe for their assistance in the development of the economic model and subsequent manuscript.

Contributors All authors contributed to the study conception and design. VP and SM contributed to the development of the economic model. Tasks relating to identification of appropriate data sources and their presentation in the manuscript were performed by WR, KKWL, VP and SM. The first draft of the manuscript was written by WR, VP and SM, and all authors commented on iterative versions of the manuscript. All authors read and approved the final manuscript.

Funding The study was funded by Medtronic.

Competing interests VP and SM are employees of York Health Economics Consortium who were commissioned by Medtronic to provide consultancy, develop the economic model and write the manuscript. CL and PM are employees of Medtronic.

Patient and public involvement Patients and/or the public were not involved in the design, or conduct, or reporting or dissemination plans of this research.

Patient consent for publication Not required.

Provenance and peer review Not commissioned; externally peer reviewed.

Data availability statement All data relevant to the study are included in the article or uploaded as supplementary information.

Open access This is an open access article distributed in accordance with the Creative Commons Attribution Non Commercial (CC BY-NC 4.0) license, which permits others to distribute, remix, adapt, build upon this work non-commercially, and license their derivative works on different terms, provided the original work is properly cited, appropriate credit is given, any changes made indicated, and the use is non-commercial. See: http://creativecommons.org/licenses/by-nc/4.0/.

\section{ORCID iDs}

William Rickets http://orcid.org/0000-0002-0475-0744

Stuart Mealing http://orcid.org/0000-0002-2564-1440

\section{REFERENCES}

1 Cancer Research UK. Cancer mortality for common cancers London: cancer research UK, 2017. Available: https://www. cancerresearchuk.org/health-professional/cancer-statistics/mortality/ common-cancers-compared\#heading-Zero

2 Royal College of Physicians. National lung cancer audit annual report 2018. London: Royal College of Physicians, 2019.

3 Goldstraw P, Chansky K, Crowley J, et al. The IASLC lung cancer staging project: proposals for revision of the TNM stage groupings in the forthcoming (eighth) edition of the TNM classification for lung cancer. J Thorac Oncol 2016;11:39-51.

4 National Lung Screening Trial Research Team, Aberle DR, Adams AM, et al. Reduced lung-cancer mortality with low-dose computed tomographic screening. N Engl J Med 2011;365:395-409.

5 National Institute for Health and Care Excellence (NICE). Lung cancer: diagnosis and management NICE guideline [NG122], 2019.

6 Callister MEJ, Baldwin DR, Akram AR, et al. British thoracic Society guidelines for the investigation and management of pulmonary nodules. Thorax 2015;70 Suppl 2:ii1-54.
7 Medtronic. SuperDimension ${ }^{\mathrm{TM}}$ navigation system, 2017. Available: https://www.medtronic.com/covidien/en-us/products/interventionallung-solutions/superdimension-navigation-system.html

8 Cancer Research UK. Survival statistics for lung cancer London: cancer research UK, 2014. Available: http://www.cancerresearchuk. org/about-cancer/type/lung-cancer/treatment/statistics-andoutlook-for-lung-cancer

9 National Institute for Health and Care Excellence (NICE). Developing NICE guidelines: the manual. London: National Institute for Health and Care Excellence, 2014.

10 Ogunsanya M, Hornby C, Shaw A, et al. 159: why are patients with lung cancer not having surgery? an investigation into variable resection rates within a multi-site NHS trust. Lung Cancer 2017;103:S73.

11 Asai N, Kawamura Y, Yamazaki I, et al. Is emphysema a risk factor for pneumothorax in CT-guided lung biopsy? Springerplus 2013;2:196.

12 Folch EE, Pritchett MA, Nead MA, et al. Electromagnetic navigation bronchoscopy for peripheral pulmonary lesions: one-year results of the prospective, multicenter navigate study. J Thorac Oncol 2019;14:445-58.

13 Office for National Statistics. National life tables. England: Office for National Statistics, 2018.

14 Hinde S, McKenna C, Whyte S, et al. Modelling the costeffectiveness of public awareness campaigns for the early detection of non-small-cell lung cancer. Br J Cancer 2015;113:135-41.

15 Zhang W, Chen S, Dong X, et al. Meta-analysis of the diagnostic yield and safety of electromagnetic navigation bronchoscopy for lung nodules. J Thorac Dis 2015;7:799-809.

16 DiBardino DM, Yarmus LB, Semaan RW. Transthoracic needle biopsy of the lung. $J$ Thorac Dis 2015;7:S304-16.

17 Sturza J. A review and meta-analysis of utility values for lung cancer. Med Decis Making 2010;30:685-93.

18 Szende A, Janssen B, Cabases J. Self-reported population health: an international perspective based on $E Q-5 D, 2014$.

19 Kind P, Hardman G, Macran S. UK population norms for EQ-5D. discussion paper, 1999.

20 McDonald K, Skinner H, Zrelak P. PS4-39 development of new harmbased weighting approach to composite indicators: the agency for healthcare research and quality patient safety for selected indicators (AHRQ PSI-90). 37th annual meeting of the Society for medical decision making, St Louis, United States of America, 2015.

21 Personal Social Services Research Unit (PSSRU). Unit costs of health \& social care. Canterbury: University of Kent, 2018.

22 Department of Health. NHS reference costs 2017-2018: NHS; 2017. Available: https://improvement.nhs.uk/resources/reference-costs/

23 BMJ Group and the Royal Pharmaceutical Society of Great Britain. British National formulary London, 2017. Available: https://www. evidence.nhs.uk/formulary/bnf/current

24 Leeflang MMG, Deeks JJ, Gatsonis C, et al. Systematic reviews of diagnostic test accuracy. Ann Intern Med 2008;149:889-97.

25 Manta C. Diagnostic accuracy of transthoracic needle aspiration (TTNA) in the evaluation of pulmonary nodules. Eur Respir J 2012;40.

26 Dale CR, Madtes DK, Fan VS, et al. Navigational bronchoscopy with biopsy versus computed tomography-guided biopsy for the diagnosis of a solitary pulmonary nodule: a cost-consequences analysis. J Bronchology Interv Pulmonol 2012;19:294-303.

27 Boskovic T, Stanic J, Pena-Karan S, et al. Pneumothorax after transthoracic needle biopsy of lung lesions under CT guidance. $J$ Thorac Dis 2014;6 Suppl 1:S99-107.

28 Abdullah R, Tavare AN, Creamer A, et al. Lung cancer tissue diagnosis in poor lung function: addressing the ongoing percutaneous lung biopsy FEV1 paradox using Heimlich valve. Thorax 2016;71:757-8.

29 Society for Medical Decision Making (SMDM). PS4-39 development of new harm-based weighting approach to composite indicators: the agency for healthcare research and quality patient safety for selected indicators (AHRQ PSI-90). 37th Annual Meeting of the Society for Medical Decision Making; October 18 - 21, 2015.

30 Cancer Research UK. Saving lives, averting costs: an analysis of the financial implications of achieving earlier diagnosis of colorectal, lung and ovarian cancer. London: Cancer Research UK, 2014. 


\section{Correction: Exploratory cost-effectiveness}

model of electromagnetic navigation

bronchoscopy (ENB) compared with CT-

guided biopsy (TTNA) for diagnosis of

malignant indeterminate peripheral

pulmonary nodules

Rickets W, Lau KKW, Pollit V, et al. Exploratory cost-effectiveness model of electromagnetic navigation bronchoscopy (ENB) compared with CT-guided biopsy (TTNA) for diagnosis of malignant indeterminate peripheral pulmonary nodules. BMJ Open Respir Res 2020;7:e00595. doi: 10.1136/bmjresp-2020-000595.

The authors want to alert readers to the following error identified in the published version.

The co-author name Nilanjan Chaudhuri has been published incorrectly as Nilanjan Chaudhari

\section{(2) \\ OPEN ACCESS}

Open access This is an open access article distributed in accordance with the Creative Commons Attribution Non Commercial (CC BY-NC 4.0) license, which permits others to distribute, remix, adapt, build upon this work non-commercially, and license their derivative works on different terms, provided the original work is properly cited, appropriate credit is given, any changes made indicated, and the use is non-commercial. See: http://creativecommons.org/licenses/by-nc/4.0/.

(C) Author(s) (or their employer(s)) 2020. Re-use permitted under CC BY-NC. No commercial re-use. See rights and permissions. Published by BMJ.

BMJ Open Resp Res 2020;7:e000595corr1. doi:10.1136/bmjresp-2020-000595corr1

D) Check for updates 